\title{
Sistem Kendali Temperature dan Humadity Pada Kotak Penyimpanan Kamera DSLR Menggunakan Metode Fuzzy Berbasis Arduino
}

\author{
Iskandar Zulkarnain, Zulfian Azmi, Ardianto Pranata, Fahrul Rivaldi Hidayat \\ STMIK Triguna Dharma
}

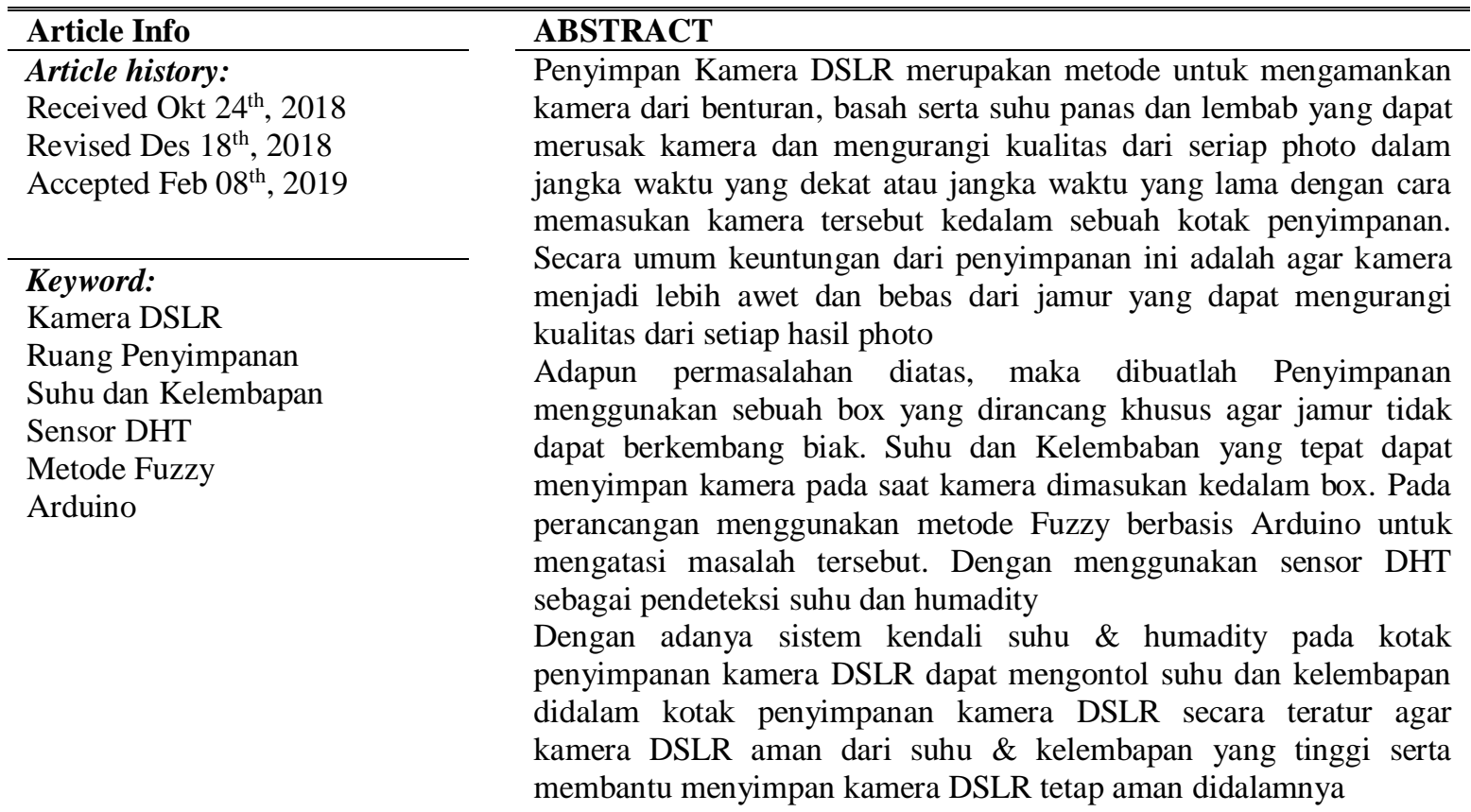

Copyright @ 2019 STMIK Triguna Dharma. All rights reserved.

\section{PENDAHULUAN}

Penyimpan Kamera DSLR merupakan metode untuk mengamankan kamera dari benturan, basah serta suhu panas dan lembab yang dapat merusak kamera dan mengurangi kualitas dari setiap gambar dalam jangka waktu yang dekat atau jangka waktu yang lama dengan cara memasukan kamera tersebut kedalam sebuah kotak penyimpanan. Secara umum keuntungan dari penyimpanan ini adalah agar kamera menjadi lebih awet dan bebas dari jamur yang dapat mengurangi kualitas dari setiap hasil photo. Tujuan dari penyimpanan kamera DSLR adalah mengurangi benturan pada body dan lensa kamera serta perkembangan jamur yang disebabkan oleh temperature dan kelembaban yang tidak sesuai dengan standar penyimpanan kamera yang benar.

Penyimpanan menggunakan sebuah box yang dirancang khusus agar jamur tidak dapat berkembang. Suhu dan Kelembaban yang tepat dapat menyimpan kamera pada saat kamera dimasukan kedalam box. Suhu dan Kelembaban didalam box pada proses penyimpanan akan memengaruhi kondisi jamur pada kamera yang dihasilkan.

Penggunaan Metode fuzzy untuk membantu menyelesaikan masalah dan penyebab dari jamur pada body dan lensa kamera DSLR, selain itu, metode fuzzy juga dapat mencari sebuah nilai yang tidak pasti untuk menentukan sebuah jawaban atau keputusan. 


\section{LANDASAN TEORI}

\subsection{Sensor DHT}

Sensor DHT 11 merupakan sensor suhu dan kelembaban udara. Range kelembaban yang dapat diukur antara $20 \%-90 \%$ RH dengan tingkat akurasi $\pm 4 \%$ RH dan sesitivitas $1 \%$ RH. DHT 11 memiliki 3 buah pin, yang terdiri dari pin VCC, DATA, dan GND. (Andrianto \& Darmanto, 2016).

\subsection{LCD 16x2}

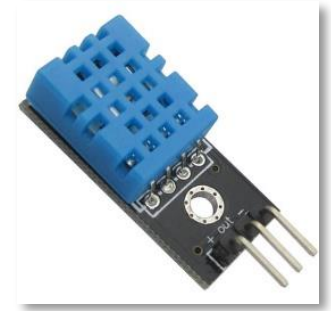

Gambar 1 Sensor DHT

LCD (liquid crystal display) 16x2 adalah suatu display dari bahan cairan Kristal yang pengoperasiannya menggunakan system dot matriks. LCD (liquid crystal display) 16x2 juga dapat menampilkan sebanyak 32 karakter yang terdiri dari 2 baris dan tiap baris dapat menampilkan 16 karakter. (Andrianto \& Darmanto, 2016)

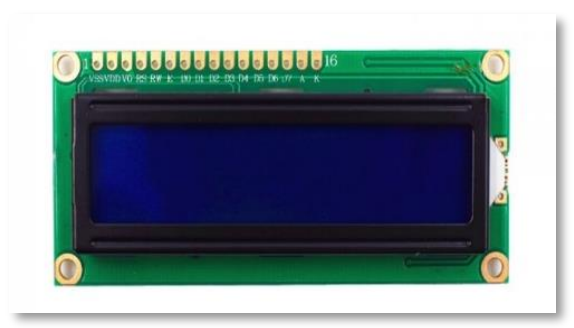

Gambar 2 LCD 16x2

\subsection{Arduino}

Arduino adalah kit elektronik atau papan rangkaian elektronika open source yang didalamnya terdapat komponen utama, yaitu sebuah chip mikrokontroler dengan jenis AVR dari perusahaan Atmel. Pembuatan arduino dimulai pada tahun 2005, pendiri dari arduino itu sendiri adalah Massimo Banzi dan David Cuartielles sebagai founder. Menurut Adriansyah, dkk (2013:102) "Arduino Uno adalah sebuah board mikrokontroler yang didasarkan pada ATmega328".

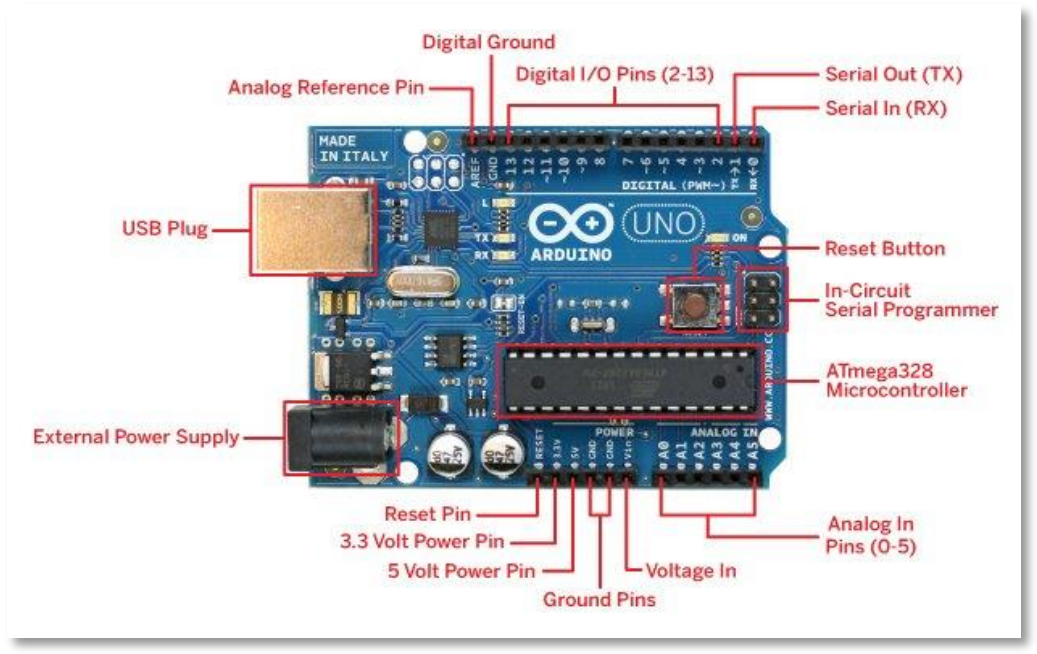

Gambar 3 Arduino

\subsection{Fuzzy}

Fuzzy logic pertama sekali di temukan Pada pertengahan 1960, oleh Prof. Lotfi Zadeh dari universitas California di Barkeley menemukan bahwa hukum benar atau salah dari logika boolean tidak 
memperhitungkan beragam kondisi yang nyata.. Fuzzy membaginya dalam derajat keanggotaan dan derajat kebenaran, yaitu sesuatu yang dapat menjadi sebagian benar dan sebagian salah pada waktu yang sama. Hal ini telah dibuktikan oleh Bart Kosko bahwa logika boolean adalah kasus kusus dari logika fuzzy. Fuzzy logic merupakan cara untuk mencari solusi atas permasalahan yang dianggap samar. (Nanda Novita, 2016)

Dalam logika klasik dinyatakan bahwa segala sesuatu bersifat biner, yang artinya adalah hanya mempunyai dua kemungkinan, "Ya atau Tidak", "Benar atau Salah", "Baik atau Buruk" dan lainya. Oleh karena itu, sistem ini dapat mempunyai nilai keanggotaan 0 atau 1. Akan tetapi, dalam logika fuzzy memungkinkan nilai keanggotaan berada di antara 0 dan 1. Artinya, bisa saja suatu keadaan mempunyai dua nilai "Ya dan Tidak", "Benar dan Salah", "Baik dan Buruk" secara bersamaan, namun besar nilainya tergantung pada bobot keanggotaan yang dimilikinya.

Logika fuzzy dapat digunakan di berbagai bidang, seperti pada sistem diagnosis penyakit (dalam bidang kedokteran), pemodelan sistem pemasaran, riset operasi (dalam bidang ekonomi), kendali kualitas air, prediksi adanya gempa bumi, klasifikasi dan pencocokan pola (dalam bidang teknik). Bila dibandingkan dengan logika konvensional, kelebihan logika fuzzy adalah kemampuannya dalam proses penalaran secara bahasa sehingga dalam perancanganya tidak memerlukan persamaan matematik yang rumit.

Himpunan fuzzy mempunyai peranan yang penting dalam perkembangan matematika khususnya dalam matematika himpunan. Matematkawan German George Cantor (1845-1918) adalah orang yang pertama kali secara formal mempelajari konsep tentang himpunan, Jantzen. Teori himpunan selalu dipelajari dan diterapkan sepanjang masa, bahkan sampai saat ini matematikawan selalu mengembangkan tentang bahsa matematika (teori himpunan). Banyak penelitian-penelitian yang menggunakan teori himpunan fuzzy dan saat ini banyak literaturelitelatur tentang himpunan fuzzy, misalnya yang berkaitan dengan teknik control, fuzzy logic dan relasi fuzzy.

\section{PEMBAHASAN DAN HASIL}

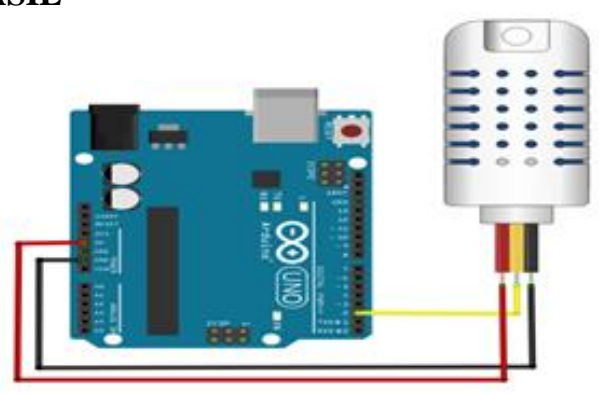

Gambar 4 Rangkaian Sensor

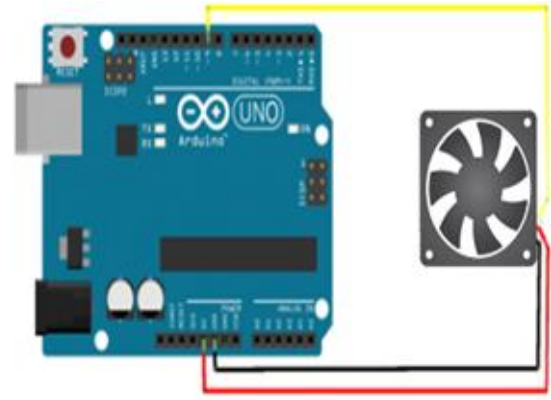

Gambar 5 Rangkaian Kipas

Penerapan Fuzzy dapat direalisasikan berupa algoritma sistem, dimana satu-satunya cara untuk membuat kategori setiap angka atau data yang terukur menjadi golongan atau kategori sesuai prinsip logika Fuzzy. Tahapan-tahapan dalam logika Fuzzy pada sistem ini adalah sebagai berikut:

1. Fuzzifiction adalah proses untuk mendapatkan derajat keanggotaan dari sebuah nilai numerik masukkan (crips).

2. Inference Rule adalah proses pembentukan aturan-aturan yang akan digunakan ke dalam suatu sistem. 
3. Defuzzification adalah proses untuk mengubah hasil penalaran yang berupa derajat keanggotaan keluaran menjadi variable numerik kembali.

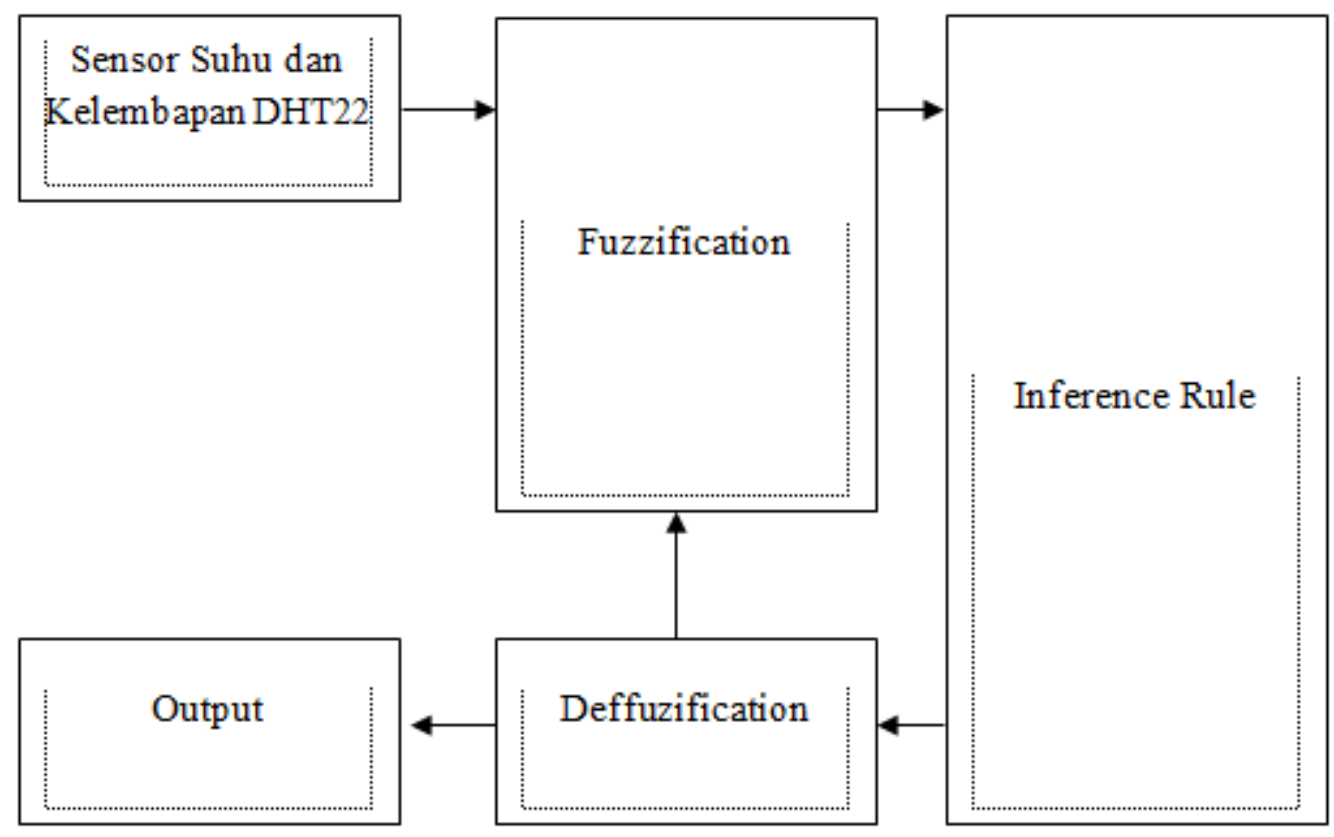

Gambar 6 Diagram Blok Proses Fuzzy

Pada diagram diatas, input an yang berasal dari sensor suhu dan Kelembaban DHT11 yang berupa nilai numerik (crips) akan dianggotakan (fuzzification). Dari derajat keanggotaan yang ada, akan dibentuk beberapa aturan (Infrencerule) yang akan digunakan ke dalam sistem. Dari aturan-aturan tersebut, didapatlah nilai keluaran yang akan diolah kembali menjadi nilai numerik (deffuzification).

Tabel 1 Variabel Fuzzy

\begin{tabular}{|c|c|c|c|c|}
\hline Fungsi & NamaVariabel & $\begin{array}{c}\text { Nama Himpunan } \\
\text { Fuzzy }\end{array}$ & $\begin{array}{c}\text { Semesta Pembicaraan } \\
\text { (Unit) }\end{array}$ & Domain \\
\hline \multirow{6}{*}{ Input } & \multirow{3}{*}{ Suhu } & Dingin & \multirow{3}{*}{ [10..100] } & [5..35] \\
\hline & & Panas & & {$[20 . .70]$} \\
\hline & & Sangat Panas & & [60..100] \\
\hline & \multirow{3}{*}{ Kelembaban } & Rendah & {$[0 . .100]$} & [0..75] \\
\hline & & Sedang & & [25..100] \\
\hline & & Tinggi & & [1] \\
\hline
\end{tabular}

1. Fuzzification

a. Derajat keanggotaan Kelembaban

Kurva untuk derajat keanggotaan pada variabel kelembaban terdiri dari 2 himpunan Fuzzy yaitu: rendah dan tinggi. 
Nilai keanggotaan Kelembaban:

$$
\begin{array}{cc}
0=x \geq 75 & 0=x \leq 25 \\
\mu \text { Rendah }[x]=(75-x) /(75-25) & \mu \text { Tinggi }[x]=(x-25) /(75-25) \\
1=x \leq 25 & 1=x \geq 75
\end{array}
$$

Bagaimana kondisi status pengiriman pesan bila input suhu 30 derajat celcius dan input Kelembaban 55 RH dengan Fuzzy?

- Derajat keanggotaan suhu (suhu 30 derajat celcius)

Nilai keanggotaan suhu (suhu 30 derajat celcius) :

$$
\begin{array}{rrr}
\mu \text { Dingin } & {[30]=(35-30) /(30-5)} & \mu \text { Normal }[30]=(70-30) /(70-20) \\
& =5 / 25 & =40 / 50 \\
& =0,2(20 \% \text { dingin }) & =0,8(80 \% \text { hangat })
\end{array}
$$

Nilai keanggotaan Kelembaban $55 \mathrm{RH}$

$$
\begin{array}{rrr}
\mu \text { Rendah }[55]=(75-55) /(75-25) & \mu \text { Tinggi }[55]=(55-25) /(75-25) \\
=20 / 50 & =30 / 50 \\
=0,4(40 \% \text { Rendah }) & =0,6(60 \% \text { Tinggi })
\end{array}
$$

Dari perhitungan di atas dåpat disimpulkan nilai keanggotaan suhu 30 derajat celcius berada $20 \%$ pada himpunan dingin dan $80 \%$ pada himpunan normal. Dan nilai keanggotaan kadar gas 55 Kelembaban berada $40 \%$ pada himpunan rendah dan $60 \%$ pada himpunan tinggi.

2. Infrencerule

Dari derajat keanggotaan tersebut, dapat dibuat beberapa aturan sesuai tabel di bawah ini:

Tabel 2 Aturan Fuzzy untuk Sistem Kontrol

\begin{tabular}{|c|l|l|l|l|}
\hline \multirow{4}{*}{ Kelembaban } & \multicolumn{3}{|c|}{ Suhu } \\
\cline { 3 - 5 } & & Dingin & Normal & Panas \\
\cline { 2 - 5 } & Rendah & Tidak Menyala & Tidak Menyala & Menyala \\
\cline { 2 - 5 } & Tinggi & Menyala & Menyala & Menyala \\
\hline
\end{tabular}

Dari definisi aturan seperti yang telah diperlihatkan pada tabel di atas, maka terdapat 6 aturan Fuzzy, yaitu:

a. If (Suhu is Dingin) And (Kelembaban is Rendah) Then (Kipas, LED \& Buzzer Tidak Menyala).

b. If (Suhu is Dingin) And (Kelembaban is Tinggi) Then (Kipas, LED \& Buzzer Menyala).

c. If (Suhu is Normal) And (Kelembaban is Rendah) Then (Kipas, LED \& Buzzer Tidak Menyala).

d. If (Suhu is Normal) And (Kelembaban is Tinggi) Then (Kipas, LED \& Buzzer Menyala).

e. If (Suhu is Panas) And (Kelembaban is Rendah) Then (Kipas, LED \& Buzzer Menyala).

f. If (Suhu is Panas) And (Kelembaban is Tinggi) Then (Kipas, LED \& Buzzer Menyala). Masukkan nilai keanggotaan ke tabel aturan, seperti tabel di bawah ini:

Tabel 3 Kombinasi Keluaran Rule

\begin{tabular}{|l|l|l|l|}
\hline \multirow{4}{*}{} & & \multicolumn{2}{|c|}{ Suhu $(30 \mathrm{C})$} \\
\cline { 3 - 4 } & & Dingin $(0,2)$ & Normal $(0,8)$ \\
\cline { 2 - 4 } Kelembaban (55 RH) & Rendah $(0,4)$ & Tidak Menyala & Tidak Menyala \\
\cline { 2 - 4 } & Tinggi $(0,6)$ & Menyala & Menyala \\
\hline
\end{tabular}

Penerapan operator $A N D$ pada nilai keanggotaan untuk menemukan bobot yang sesuai. Pilih nilai munimum karena menggunakan operator $A N D$.

Suhu $=\{0.2,0.8\} \longrightarrow$ Kelembaban $=\{0.4,0.6\}$

Suhu $\cap$ Kelembaban $=\{\operatorname{MIN}(0.2,0.4), \operatorname{MIN}(0.2,0.6), \operatorname{MIN}(0.8,0.4), \operatorname{MIN}(0.8,0.6)\}$

$$
=\{0.2,0.2,0.4,0.6\}
$$


Masukkan nilai yang telah diterapkan operator $A N D$ ke tabel, seperti tabel di bawah ini:

Tabel 4 Penerapan Operator $A N D$

\begin{tabular}{|l|l|l|l|}
\hline \multirow{4}{*}{} & & \multicolumn{2}{|c|}{ Suhu (30 C) } \\
\cline { 3 - 4 } & & Dingin $(0,2)$ & Hangat $(0,8)$ \\
\cline { 2 - 4 } & Rendah $(0,4)$ & 0.2 & 0.4 \\
\cline { 2 - 4 } Kelembaban (55 RH ) & Tinggi $(0,6)$ & 0,2 & 0.6 \\
\hline
\end{tabular}

\section{Defuzzification}

Setelah mendapatkan nilai dari penerapan operator AND, diperolehlah:

$f=\{($ Tidak Menyala), (Tidak Menyala), (Tidak Menyala), (Menyala) $\}$

$=\{0.2,0.2,0.4,0.6\}=0,6$ (Menyala)

Penentuan hasil akhir dengan menggunakan metode Max Method pada fuzzy mamdani, yaitu dengan mengambil nilai tertinggi yaitu " 0,6 " dengan hasil "Menyala".

Jadi, apabila input suhu 30 derajat celcius dan input Kelembaban 55 RH maka output adalah Kipas Menyala.

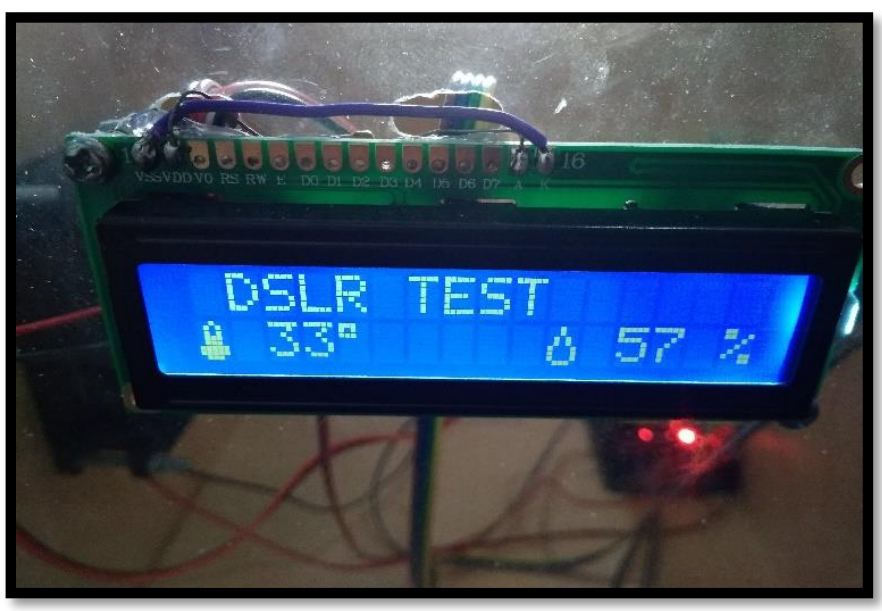

Gambar 7 Hasil Pendeteksian Suhu dan Kelembapan

Pengujian ini dilakukan guna mengetahui apakah sensor suhu LM35 berfungsi sesuai kebutuhan sistem dengan cara memberikan program kedalam mikrokontroler ATmega32 sehingga sensor DHT 11 dapat mendeteksi suhu di sekitar sensor. Dengan demikian dapat diketahui bahwa sistem sudah bekerja atau tidak. Berikut tabel pengujian sensor suhu \& kelembaban DHT 11.

Tabel 5 Pengujian Sistem Secara Keseluruhan

\begin{tabular}{|c|c|c|c|c|}
\hline No & Suhu $\left({ }^{\circ} \mathbf{C}\right)$ & $\begin{array}{c}\text { Kelembaban } \\
(\mathbf{P P M})\end{array}$ & Kategori & Keterangan Kipas \\
\hline \multirow{2}{*}{1} & \multirow{2}{*}{$0-30$} & $0-200$ & Dingin AND Rendah & Kipas Pelan \\
\cline { 3 - 5 } & \multirow{2}{*}{2} & $250-500$ & Dingin AND Tinggi & Kipas Cepat \\
\hline \multirow{2}{*}{3} & \multirow{2}{*}{$20-50$} & $0-200$ & Normal AND Rendah & Kipas Pelan \\
\cline { 3 - 5 } & \multirow{2}{*}{$40-80$} & $250-500$ & Normal AND Tinggi & Kipas Cepat \\
\cline { 3 - 5 } & & $0-200$ & Panas AND Rendah & Kipas Pelan \\
\hline
\end{tabular}

\section{KESIMPULAN}

Adapun kesimpulan yang dapat diambil dari rangkaian dan sistem keseluruhan implementasi metode fuzzy untuk pengukuran sistem kendali temperature dan humadity pada kotak penyimpanan kamera DSLR berbasis arduino adalah sebagai berikut : 
1. Dalam merancang alat penyimpanan kamera DSLR dibutuhkan ketelitian dalam menentukan rancang bangun dan komponen elektronika untuk mendapatkan hasil yang diinginkan.

2. Alat pengukuran suhu dan kelembaban kotak penyimpanan kamera DSLR otomatis berbasis arduino di rancang dengan menggunakan sensor suhu dan kelembaban yang berfungsi sebagai input, dan sebagai output nya menggunakan lcd untuk menampilkan intensitas suhu dan kelembaban.

3. Metode fuzzy diterapkan pada input-an suhu dan kelembaban dalam menentukan kecepatan putaran pada kipas dan menampilkan level suhu dan kelembaban pada lcd.

4. Pada sistem ini pengukuran sistem pendingin rungan genset akan disesuaikan dengan kondisi tingkat intensitas suhu dan kelembaban yang terdeteksi oleh sensor DHT 22.

5. Sebagai output yaitu LCD dan Kipas yang bekerja untuk menampilkan hasil dari pendeteksian sensor suhu dan kelembaban serta untuk mengeluarkan atau mengurangi intensitas lembab dan suhu panas didalam kotak penimpanan agar tidak terjadi perkembang biakan jamur yang dapat menyebabkan kerusakan pada Body dan Lensa kamera.

\section{REFERENSI}

[1] Andrianto, A \& Darmawan, A (2016). Arduino Belajar Cepat Dan Pemerograman, Bandung : Informatika Januari 2016

[2] Ardiansyah, A., (2013). Rancang Bangun Prototipe Elevator Menggunakan Microcontroller Arduino Atmega 328p. Dari http://publikasi.mercubuana.ac.id/index.php/jte/article/view/753

[3] Fuad, A, (2015). Kajian Penambahan Manfaat Energi Genetik Kipas Angin Rumahan, Inosains, Vol. 10, No. 2, Agustus 2015

[4] Islam, I., Nabilah, N., \& Kurniawan, A., (2016). Sistem Kendali Suhu Dan Pemantauan Kelembaban Udara Ruangan Berbasis Arduino Uno Dengan Menggunakan Sensor Dht22 Dan Passive Infrared (Pir). Dari https://www.researchgate.net/profile/Ade_Kurniawan10/publication/313225561

[5] Lumbanbatu, K \& Novriyeni., (2013) Perancangan Sistem Informasi Penyebaran Penduduk Menggunakan PHP Mysql Pada Kecamatan Binjai Selatan Dari penelitian.kaputama.ac.id/images/sampledata/File/Jurnal/Jurnal2013/JURNAL8.pdf

[6] Novita, N., (2016) Metode Fuzzy Tsukamoto Untuk Menentukan Beasiswa dari https://jurnal.polgan.ac.id/index.php/sinkron/article/download/11/26/

[7] Saptadi, H,A., (2014). Perbandingan Akurasi Pengukuran Suhu dan Kelembaban Antara Sensor DHT11 dan DHT22 Studi Komparatif pada Platform ATMEL AVR dan Arduino Dari http://ejournal.st3telkom.ac.id/index.php/infotel/article/view/16

[8] Saptadi, H. A, \& Arifin, J., (2016) Sistem Pemantau Suhu Dan Kelembaban Ruangan Dengan Notifikasi Via Email. Dari https://www.unisbank.ac.id/ojs/index.php/sendi_u/article/view/4161

[9] Setiawan, A, I, S., (2011) Google SketchUp Perangkat Alternatif Dalam Permodelan Dari ejournals.umn.ac.id/index.php/TI/article/view/298/264 